\title{
A educação financeira no contexto da biopolítica e da governamentalidade
}

\author{
Financial education in the context of biopolitics and governmentality \\ La educación financiera en el contexto de la biopolítica y la gubernamentalidad
}

Recebido: 22/12/2021 | Revisado: 29/12/2021 | Aceito: 19/02/2022 | Publicado: 01/03/2022

\author{
Neivaldo Rodrigues dos Santos \\ ORCID: https://orcid.org/0000-0002-5761-0083 \\ Afya-São Lucas, Brasil \\ E-mail: economistaneivaldo@gmail.com \\ Rafael Christofoletti \\ ORCID: https://orcid.org/0000-0003-2752-8596 \\ Universidade Federal de Rondônia, Brasil \\ E-mail: rafael.c@unir.br
}

\begin{abstract}
Resumo
A biopolítica é um termo desenvolvido por Foucault para designar um conjunto de práticas de controle gestão e da vida das populações, desenvolvido pelos estados, em sua maioria os neoliberais, como forma de estabelecer a governamentalidade, que por sua vez, necessita instituir as desigualdades sociais para a organização da racionalidade política. Neste cenário, a escola é um espaço para a consolidação dos interesses da elite como forma de perpetuar seu status quo. No caso do Brasil, percebe-se inúmeras manifestações de práticas biopolíticas na educação, como a proliferação de políticas educacionais seguindo a ordenação do mercado. Este texto tem por objetivo discutir a educação financeira a partir dos conceitos foucaultianos de governamentalidade e biopolítica como sociedade disciplinar que estrutura o controle de classe e de sociedade, visando sempre a manutenção da ordem e da moral. Trata-se de um recorte da dissertação de mestrado "Educação Financeira e Educação Menor: experimentações curriculares com uma turma de $9^{\circ}$ ano em Ji-Paraná/RO”, desenvolvida junto ao Programa de Pós-Graduação em Educação Escolar - Mestrado e Doutorado Profissional (PPGEEProf), da Universidade Federal de Rondônia.
\end{abstract}

Palavras-chave: Biopoder; Governamentalidade; Educação; Educação financeira.

\begin{abstract}
Biopolitics is a term developed by Foucault to designate a set of management control practices and the life of populations, developed by states, mostly neoliberals, as a way to establish governmentality, which in turn needs to institute social inequalities for the organization of political rationality. In this scenery, the school is a space for the consolidation of the interests of the elite as a way to perpetuate its status quo. In the case of Brazil, there are numerous manifestations of biopolitical practices in education, such as the proliferation of educational policies following the market ordination. This text aims to discuss financial education based on foucaultian concepts of governmentality and biopolitics as a disciplinary society that structures class and society control, always aiming at maintaining order and morality. This is a section of the master's thesis "Financial Education and Minor Education: curricular experiments with a 9th year class in Ji-Paraná/RO", developed with the Graduate Program in School Education - Master and Professional Doctorate (PPGEEProf), of the Federal University of Rondônia.
\end{abstract}

Keywords: Biopower; Governmentality; Education; Financial education.

\section{Resumen}

La biopolítica es un término desarrollado por Foucault para designar un conjunto de prácticas de control de gestión y la vida de las poblaciones, desarrolladas por los estados, en su mayoría neoliberales, como una forma de establecer la gubernamentalidad, que a su vez necesita instituir desigualdades sociales para la organización de la racionalidad política. En este escenario, la escuela es un espacio para la consolidación de los intereses de la élite como una forma de perpetuar su status quo. En el caso de Brasil, existen numerosas manifestaciones de prácticas biopolíticas en la educación, como la proliferación de políticas educativas tras el ordenamiento del mercado. Este texto tiene como objetivo discutir la educación financiera basada en los conceptos foucaultianos de la gubernamentalidad y la biopolítica como una sociedad disciplinaria que estructura el control de clase y sociedad, siempre con el objetivo de mantener el orden y la moral. Esta es una sección de la tesis de maestría "Educación Financiera y Educación Menor: experimentos curriculares con una clase de $9^{\circ}$ año en Ji-Paraná / RO", desarrollada con el Programa de Posgrado en Educación Escolar - Maestría y Doctorado Profesional (PPGEEProf), de la Universidad Federal de Rondônia.

Palabras clave: Biopoder; Gubernamentalidad; Educación; Educación financiera. 


\section{Introdução}

Na sociedade brasileira, a educação está intrinsicamente relacionada aos interesses do Estado que, costumeiramente, se organiza para atendar aos objetivos e interesses de uma elite dominante. Grosso modo, os processos educacionais do país costumam se destinar tanto à elite, quanto à classe trabalhadora. Contudo, são processos com objetivos diferenciados, à primeira se estabelece um aprendizado com intuito à manutenção de seu poder; à segunda se ofertam conhecimentos que perpetuem a estrutura da ordem. Apesar de objetivos específicos para cada uma dessas classes sociais, o objetivo final deste processo educacional é sempre consolidar os interesses da elite para a manutenção de seu status quo.

Em rápida análise de conjuntura histórica da educação brasileira é possível observar que a totalidade societária se caracterizou, ao longo de cinco séculos, pela consolidação da burguesia local, subordinada ao capital internacional. Esta condição se manifestou nas políticas educacionais colocadas em prática desde os governos monárquicos, passando pelas distintas fases de organização de poder na República até chegar aos dias atuais, sempre utilizando o sistema educacional do país como instrumento de salvaguarda ideológica para o Estado e para a manutenção de comando da elite dominante (Santos, 2005).

Como parte dos currículos escolares, a educação financeira se insere no contexto descrito acima e rigorosamente, é apresentada sob um viés capitalista, com orientações para os lucros, compras e acumulação de bens pessoais. Dentre algumas definições sobre educação financeira, Savóia et al (2007) a compreendem como promotora de investigações sobre a importância do dinheiro e sua administração, um aprendizado que resulta na execução de um planejamento financeiro pessoal de curto, médio ou longo prazo, com a finalidade de garantir o bem-estar econômico e financeiro das pessoas.

De forma geral, os objetivos da educação financeira consistem na apropriação e utilização, pelos indivíduos e seus grupos sociais, das tecnologias inerentes à matemática financeira, de planilhas eletrônicas e dos conceitos de dinheiro. São mesmo objetivos capazes de melhorar a qualidade de vida de grupos sociais mais vulneráveis economicamente, o trabalho de letramento financeiro pode contribuir para que as pessoas gerenciem suas próprias vidas.

Contudo, educação financeira é mais do que apenas saber fazer contas, elaborar e cumprir um orçamento doméstico, pesquisar preços, evitar dívidas, poupar e investir. Nem todos os problemas financeiros podem ser resolvidos apenas com a matemática, pois neste caso não faltaria dinheiro, erros como "gastar mais do que se tem" não seriam cometidos. Uma possibilidade muito salutar é abordá-la sob o ponto de vista do consumo judicioso, gerando conceitos que permitam às pessoas ter ciência dos impactos negativos e positivos que suas decisões podem provocar na sociedade e no meio ambiente, somente a educação voltada para o consumo sensato é que pode proporcionar uma mudança eficaz de comportamento dos consumidores alienados (Efing \& Resende, 2016). Assim, a Educação financeira pode auxiliar na construção de comportamentos que valorizem o "cuidar de si" e o cuidar do ambiente.

Este texto tem por objetivo discutir a educação financeira inserida nos processos educacional brasileiro a partir do contexto do biopoder abordado por Foucault (1987) que estrutura o controle de classe e de sociedade, visando sempre a manutenção da ordem e da moral vigentes através dos processos disciplinares.

\section{Metodologia}

Este texto é um recorte da dissertação de mestrado "Educação Financeira e Educação Menor: experimentações curriculares com uma turma de $9^{\circ}$ ano em Ji-Paraná/RO”, desenvolvida junto ao Programa de Pós-Graduação em Educação Escolar - Mestrado e Doutorado Profissional (PPGEEProf), da Universidade Federal de Rondônia, com protocolo de registro junto ao CEP nº 29838820.4.0000.5300, aprovação pelo Parecer nº 3.960.571. 
A metodologia utilizada para o desenvolvimento da pesquisa de mestrado foi a pesquisa-intervenção (Aguiar e Rocha, 2003), com embasamento nos conceitos teóricos de educação menor, estruturados pelo pedagogista S. Gallo (2002, 2013, 2020). Contudo, o presente recorte que compõem um dos capítulos da dissertação foi construído a partir das diretrizes da pesquisa bibliográfica que conforme Prodanov e Freitas (2013) é aquela elaborada a partir de material já publicado, constituído principalmente de: livros, revistas, publicações em periódicos e artigos científicos, dissertações, teses, internet, entre outros, que permite ao pesquisador acesso direto com outras produções sobre o assunto da pesquisa.

\section{Resultados e Discussão}

Para Foucault (2008a), o conhecimento está intrinsecamente relacionado ao poder ou é base para a sua consumação. Para a execução do poder, contudo, é necessário transcender o conhecimento superficial ou senso comum, é preciso um aprofundamento à episteme que envolve questões além das racionalidades efetivadas, depende do momento histórico, da sociedade e do discurso enquanto conjunto de pensamentos originários das relações de poder presentes nesta sociedade. Foucault acredita que a episteme pode ser entendida como:

[...] o conjunto das relações que podem unir, em uma dada época, as práticas discursivas que dão lugar a figuras epistemológicas, as ciências, eventualmente à sistemas formalizados; o modo segundo o qual, em cada uma dessas formações discursivas se situam e se realizam as passagens à epistemologização, à cientificidade. [...] A episteme não é uma forma de conhecimento, racionalidade que, atravessando as ciências manifestaria a unidade soberana de um sujeito, de um espírito ou de uma época; é o conjunto das relações que podem ser descobertas, para uma época dada, entre as ciências, quando estas são analisadas no nível das regularidades discursivas (2008a, p.157).

Desde a Idade Média, no nível das regularidades discursivas, a educação sempre foi representante do domínio do saber, perpassando por ela infinitas práticas, discursos e movimentos de disputa com diferentes visões de mundo e interesses políticos. Dessa forma, a educação legitimou-se como um dos principais instrumentos para a afirmação do poder. No campo de produção do saber promoveu o encontro de diversos saberes: pedagogia, economia, psicologia, sociologia, filosofia, entre outros, gerando assim, campos produtores de diversos jogos de poder, gerando forças diferentes e efeitos variados. Neste contexto, a escola é analisada de maneira simplista e reducionista, e talvez por isso, seja uma instituição onde tensões e relação de poder ganham maior visibilidade.

Mesmo para as sociedades ocidentais, a escola é uma instituição relativamente moderna, o que significa dizer que se educava e aprendia-se antes, de diferentes maneiras (Grupo Transversal, 2015). Somente a partir de meados do século XVIII, sob a emergência das sociedades industriais, é que o modelo de escola conhecido e praticado hoje, se constituiu. Trata-se de uma instituição criada em semelhança às fábricas e às prisões, onde as estruturas se organizam para distribuir os corpos no tempo e no espaço; aplicar a todos o mesmo programa baseado na disciplina e na domesticação; definir parâmetros esperados para a saída; conferir a qualidade dos produtos no fim do processo, liberar os adequados e reter os desajustados, aplicando-lhes os castigos e as correções que melhor convir e repetir infinitamente os mesmos processos, objetivando garantir uma padronização em escala (Foucault, 1987).

A partir do momento em que se delegou a escola trabalhar a disciplina inspirada em modelos de uma fábrica industrial, a educação efetivou a continuidade dos processos disciplinares, as componentes curriculares se tornaram suporte para uma nova ordem social submetida ao controle de classe e de sociedade, visando a continuidade das diferenças e, principalmente, dos privilégios sociais com a manutenção da ordem e da moral vigentes (Foucault, 1987).

Entretanto, com o aperfeiçoamento das técnicas de poder, no advento das sociedades modernas, surgiram também diversas formas de resistência e de críticas às instituições escolares do mundo ocidental, como aparelhos disciplinares e reprodutoras das estruturas de poder da burguesia, cuja finalidade era produzir políticas que interferissem na ordem vigente e 
diminuíssem as desigualdades, contribuindo para a transformação social. Os movimentos de resistência à esta escola, vinculada às estruturas burguesas foram analisados por Deleuze (1998, apud Grupo Transversal):

Nesta perspectiva, o trabalho do educador apresenta-se como uma resistência ao já dado, aos saberes constituídos que reproduzem formas de dominação, de discriminação, de preconceitos, carregando a vida de valores que a impedem de afirmar aquilo que ela pode. Trata-se então, de colocar-se na corrente da vida, proceder de modo a afirmar a vida, tornando-a leve e ativa, pois, só existe criação propriamente dita na medida em que, longe de separar a vida daquilo que ela pode, nos servimos do excedente para inventar novas formas de vida (2015, p.103).

A partir do século XX, diversos pensadores e profissionais da educação se propuseram a questionar as práticas disciplinares silenciosas e abusivas da escola, na tentativa de romper com os padrões de comportamento vigente, tais como filas no pátio, de carteira na sala de aula, prédios organizados segundo as atividades, controle de frequência, avaliações, exames, provações e reprovações, legitimação de determinado currículo, condutas impostas, controle de vestimentas, entre outras tantas regras vigentes. Este modelo de escola se insere na consolidação da Modernidade, conforme argumenta Foucault:

A ordenação por fileiras, no século XVIII, começa a definir a grande forma da repartição dos indivíduos na ordem escolar: filas de alunos na sala, nos corredores, nos pátios; colocação atribuída a cada um em relação a cada tarefa e cada prova; colocação que ele obtém de semana em semana, de mês em mês, de ano em ano; alinhamento das classes de idade uma depois das outras; sucessão dos assuntos ensinados, das questões tratadas segundo uma ordem de dificuldade crescente. E nesse conjunto de alinhamentos obrigatórios, cada aluno segundo sua idade, seus desempenhos, seu comportamento, ocupa ora uma fila, ora outra; ele se desloca o tempo todo numa série de casas; umas ideais, que marcam uma hierarquia do saber ou das capacidades, outras devendo traduzir materialmente no espaço da classe ou do colégio essa repartição de valores ou dos méritos. Movimento perpétuo onde os indivíduos substituem uns aos outros, em espaço escondido por intervalos alinhados (1987, p. 173).

Essa estrutura de organização e de controle do espaço é complementada com um monitoramento do tempo.

Acrescentando, o autor afirma que:

Esse é o tempo disciplinar que se impõe pouco a pouco à prática pedagógica - especializando o tempo de formação e destacando-o do tempo de adulto, do tempo do ofício adquirido; organizando diversos estágios separados uns dos outros por provas graduadas; determinando programas, que devem desenrolar-se cada um, durante uma determinada fase e que comportam exercícios de dificuldade crescente; qualificando os indivíduos de acordo com a maneira como percorreram essas séries. O tempo "iniciático" da formação tradicional (tempo global, controlado só pelo mestre, sancionado por uma única prova) foi substituído pelo tempo disciplinar com suas séries múltiplas e progressivas. Forma-se toda uma pedagogia analítica, muito minuciosa (decompõe até aos mais simples elementos a matéria do ensino, hierarquiza no maior número possível de graus cada fase do progresso) e também muito precoce em sua história (antecipa largamente as análises genéticas dos ideólogos dos quais aparece como o modelo técnico) (1987, p. 184-185).

Olhando para as escolas, atualmente, percebe-se a presença da inspeção permanente com mecanismos de controle em aplicação tecnológica da imagem. Boa parte das escolas brasileiras já contam hoje com a instalação de câmeras para vigilância nos pátios, nos corredores e nas salas de aula, sempre em nome da segurança. Mas, é possível tentar retirar a educação desse processo de controle, para pensá-la não somente como transmissão, assimilação e imposição de conteúdos e sim, como um local acessível aos processos de mudança, de transformação, rumo a uma nova ordem e de produção singular, em diferentes territórios (Mascarenhas, 2018).

Isto implica em pensar uma educação composta por currículos flexíveis, que se desenvolvem considerando os acontecimentos da vida e das múltiplas faces que ela apresenta, construir conhecimentos que atravessem as barreiras rígidas impostas pelo capitalismo moderno, propondo outras estruturas curriculares e, dessa maneira, criar novos valores para a educação, visando possibilidades de uma vida alegre e potente. 
Porém, as mudanças do modelo de produção capitalista, somadas aos processos da globalização e ao neoliberalismo, impõem dificuldades e até mesmo ameaçam as experiências progressistas na educação, quando exigem que todas as suas ações se tornem registráveis e adaptáveis aos processos produtivos. Nesse sentido, Deleuze e Guattari (2010) afirmam que a máquina capitalista atua, de um lado, extraindo tudo o que seja possível para a máxima utilidade e produtividade, e de outro, diminuindo a sua potência para rebaixar a vida.

As tentativas de resistência geralmente são enfraquecidas, multiplicam-se os riscos, crescem a burocratização e a institucionalização das práticas educativas que, por sua vez, transformam os educadores em meros administradores escolares ou reprodutores de conteúdos pré-determinados por um ementário. Os educadores passam a conviver com normas legais que se contrapõem às possibilidades da criação de práticas pedagógicas alternativas, quando tais normas limitam ou mesmo impossibilitam a efetivação de novas experiências educacionais. Nesta realidade, o trabalho dos professores costuma ser precário, as escolas são pressionadas a desenvolverem, majoritariamente, atividades voltadas ao conteudismo, desvalorizando as particularidades e os saberes locais da comunidade e propondo modos de vida embasados em padrões comportamentais que satisfaçam a manutenção do status quo.

Como forma de resistência para enfrentar os processos de massificação instaurados pelo modo de produção vigente, uma das possibilidades que se apresenta é a educação menor, elaborada pelo filósofo pedagogista S. Gallo ${ }^{1}$, e que territorializa-se, isto é, ocupa espaços, colocando-se como possibilidades outras para a construção da existência.

\subsection{Educação, poderes disciplinares e biopolítica}

Mascarenhas (2018) lembra que, atualmente, multiplicam-se terminologias como neoliberalismo, globalização, sociedade de informação e conhecimento, capitalismo cultural, pós-fordismo, dentre muitas outras. Estas terminologias representam modos específicos de pensar e, sobretudo, de viver, se cristalizam e se massificam no interior da sociedade, impedindo que outras formas de vivência aconteçam. Mas, atualmente, como são fabricados mundos prontos para a habitação de formas determinadas, ou as formas prontas para habitarem determinados mundos, em detrimento de outros mundos?

Buscam-se possíveis respostas a este questionamento, através de análises sobre a "biopolítica", o termo foi utilizado por Foucault para designar um conjunto de práticas de controle gestão e da vida das populações e desenvolvido pela articulação de duas maneiras distintas de saber poder: por um lado, as disciplinas oriundas no século XVII, dedicadas ao adestramento do corpo, sua organização e extração das utilidades de suas forças; de outro lado, a regulamentação e o controle das populações que, principalmente, na Europa, passaram a apresentar um rápido crescimento populacional, a partir da segunda metade do século XVIII. (Mascarenhas, 2018).

Para Foucault (1988) nasce uma nova forma de poder, centrada em dispositivos disciplinares, encarregados de extrair do corpo humano a sua força produtiva, o biopoder, a expressão maior da biopolítica:

[...] deveríamos falar de 'biopolítica' para designar o que faz com que a vida e seus mecanismos entrem no domínio dos cálculos explícitos, e faz do poder- saber um agente de transformação da vida humana [...]. Não é necessário insistir, também, sobre a proliferação das tecnologias políticas que, a partir de então, vão investir sobre o corpo, a saúde, as maneiras de se alimentar e de morar, as condições de vida, todo o espaço da existência (1988, p. 134- 135).

\footnotetext{
1 Ver:

Gallo, S. (2002) disponível em: https://seer.ufrgs.br/index.php/educacaoerealidade/article/view/25926;

Gallo, S. (2013) disponível em:

http://36reuniao.anped.org.br/pdfs_trabalhos_encomendados/gt13_trabencomendado_silviogallo.pdf;

Gallo, S \& Monteiro, A. (2020) disponível em:

http://www.rematec.net.br/index.php/rematec/article/view/228.
} 
Esse biopoder diferencia-se do poder disciplinar, uma vez que a finalidade não é somente monitorar comportamentos individuais, mas estabelecer controle sobre as condutas e normas da espécie humana. Entretanto, para Foucault o biopoder age com a intenção de "[...] distribuir os vivos em um domínio de valor e utilidade" (1988, p. 135). Tal poder naturalizará os códigos de conduta, selecionando conhecimentos e impondo discursos de ordem judicial, médica, linguística, religiosa, doméstica, etc.; produzirá alguns modelos de pensamento, ignorando outros, os quais considera inúteis, improdutivos, perigosos, anormais e inconformes (Mascarenhas, 2018).

A biopolítica pressupõe a transmutação das sociedades da disciplina, para levar ao aperfeiçoamento de práticas de assujeitamento, é o que corresponde ao que foi determinado por Deleuze (1992), quando nominou sociedades de controle. Se as sociedades da disciplina estavam marcadas pelo controle e também pelo confinamento, as sociedades de controle são operadas por meio de práticas sem forma, difusas e sutis, mas sentidas diretamente no corpo. Veja-se:

Os confinamentos são moldes, distintas moldagens, mas os controles são uma modulação, como uma moldagem autodeformante que mudasse continuamente, a cada instante, ou como uma peneira cujas malhas mudassem de um ponto a outro [...]. Os indivíduos tornam-se dividuais, divisíveis, e as massas tornaram-se amostras, dados, mercados ou bancos (1992, p. 221-222).

As sociedades da disciplina estavam baseadas na propriedade dos meios de produção, por instituições disciplinadoras e centralizadas (as fábricas, a própria família, os hospitais, os manicômios, as prisões, as escolas), com a lógica de organizar e concentrar, distribuindo os corpos pelos espaços em uma economia de produção em massa. Foucault (1987) comparou, de forma bastante crítica, o corpo do estudante ao lado dos corpos do presidiário, do doente e do operário. Para todos esses corpos, as práticas disciplinares são similares, definem o tempo e movimentos precisos, organizam os corpos no tempo e no espaço e corrigem as posturas. São a modelagem, o treinamento e a correção como mecanismos de poder e de saber, que se voltam contra o corpo, neste sentido, Foucault também argumenta que:

Uma 'anatomia política', que é também igualmente uma 'mecânica do poder', está nascendo; ela define como se pode ter domínio sobre os corpos dos outros, não simplesmente para que façam o que se quer, mas para que se operem como quer, com as técnicas, segundo a rapidez e a eficácia que se determina. A disciplina fabrica assim corpos submissos e exercitados, corpos 'dóceis'. A disciplina aumenta as forças do corpo (em termos econômicos de utilidade) e diminui essas mesmas forças (em termos políticos de obediência) (1987, p. 119).

Nas instituições escolares, as práticas disciplinares são bem visíveis e presentes na estrutura arquitetônica dos prédios e nas disposições da sala de aula, que determinam modos consolidados de ocupação. A determinação postural com o posicionamento dos corpos, modos de sentar, de falar, de ouvir; a grande valorização de conhecimentos abstratos em detrimento dos de vida, adquiridos no cotidiano do estudante e a desvalorização de saberes capazes de mobilizar de outras maneiras o corpo na escola, tais como a dança, a música, o teatro e a educação física.

Neste mesmo processo de práticas disciplinares, presentes nas escolas, estão a imposição de ciclos de formação, a serialização e a divisão de conteúdo, a estratificação dos tempos de aprendizagem, os bimestres, as avaliações periódicas e a verificação contínua sobre o aprendizado e o comportamento, determinando o que, como e quando aprender. Estas práticas se fundamentam em uma forma de obediência que busca domesticar não somente o corpo, mas também a alma do estudante.

Entretanto, no advento da sociedade globalizada, o controle sobre os corpos tem se tornado mais abstrato e difuso, com trocas flutuantes e que não passam mais por confinamentos e disciplinas. $\mathrm{O}$ trabalho na fábrica pode ser trocado pelo teletrabalho, determinado apenas pelo cumprimento de metas de produtividade; na educação, sobretudo nestes tempos de pandemia, o espaço escolar foi trocado pela educação a distância e por ciclos formativos exigidos pelo mercado. Como lembra Mascarenhas (2018), as máquinas energéticas das sociedades disciplinares cederam lugar às tecnologias computacionais, à 
biotecnologia e à inteligência artificial; até o dinheiro se torna gradativamente obsoleto, mais abstrato e a moeda está sendo substituída por transações financeiras eletrônicas.

Em especial, no caso do Brasil, percebe-se inúmeras manifestações de práticas biopolíticas na educação, como a proliferação de políticas educacionais seguindo a ordenação do mercado, a exemplo do "empreendedorismo" e o aumento da procura acadêmica por cursos de interesses, determinados pelo mercado.

Um exemplo é o ingresso em cursos de Medicina e Engenharias, enquanto que os cursos nas áreas de Ciências Humanas e de Licenciatura (Pedagogia, Química, Física, dentre outras), sempre registram baixa procura. Além disso, as condições financeiras precárias das escolas e universidades; as privatizações sob a forma de terceirização setorial; a militarização do ensino público; o crescimento de cursos técnicos pós-médio e graduações tecnológicas de formação rápida para atender às necessidades de mão de obra especializada e mais barata ao mercado de trabalho e, por fim, a transformação tácita do professor em gestor são exemplos de políticas educacionais estruturadas no biopoder e impondo conformismo e vivências de modos específicos, engessados e alheios às diferenças e mudanças.

No caso dos professores, especificamente, encontram-se sob o estado de abatimento geral, uma paralisação e uma diminuição na vontade de agir, escassez de imaginação política e descrença do mundo. São ilações contínuas no processo de automação das subjetividades, entrementes, são levados a reproduzir e estabelecer relações tímidas e com pouca flexibilidade. Estes comportamentos são também resultados de uma governamentalidade educacional que, como nos asseguram Lima e Silva (2021), podem criar diversas expectativas em torno da produção de um ensino voltado à produtividade máxima, como forma de potencializar o chamado capital humano.

O excesso de informação disponível em variadas formas e dispositivos (aplicativos para celular, redes sociais, que modelam comportamentos e limitam a observação das diferenças) inclui uma significativa parcela da sociedade numa bolha virtual, com controle por inteligência artificial e algoritmo, com exposição de imagens inúteis e fugazes (Larrosa, 2002), provoca transformações nas relações sociais, trabalhistas e na produção exigente de uma super produtividade como caracterização de trabalho remoto, ameaças de rebaixamento do emprego ou a sua perda.

A constante sensação de viver em um tempo acelerado, com excesso de tarefas a serem realizadas, geram sentimentos de auto cobrança, de diluição e esvaziamento dos sentidos da existência, causados também pela grande exposição do indivíduo às imagens, aos signos, aos estímulos sonoros e visuais que permeiam a vida cotidiana atual. No geral, estão expostos a um turbilhão de informações, confundindo qualidade com quantidade, quando chamados a se expressar e a dar opinião (Mascarenhas, 2018), sem, no entanto, ter tempo suficiente para reflexão. Deleuze (1992) já defendia a necessidade do silêncio:

[...] e estamos trespassados de palavras inúteis, de uma quantidade demente de falas e imagens. A besteira nunca é muda nem cega. De modo que o problema não é mais fazer com que as pessoas se exprimam, mas arranjar-lhes vacúolos de solidão e de silêncio a partir dos quais elas teriam, enfim, algo a dizer. As forças repressivas não impedem as pessoas de se exprimir, ao contrário, elas as forçam a se exprimir. Suavidade de não ter nada a dizer, direito de não ter nada a dizer; pois é a condição para que forme algo raro ou rarefeito, que merecesse um pouco ser dito (1992, p. 161-162).

Vivem-se tempos que carecem do silêncio para refletir e melhor compreender o mundo acelerado desta sociedade da informação, distinta da sociedade do conhecimento, como adverte Larrosa (2002). Tem-se, também, excesso de trabalho, fruto do grande processo de transformação da economia e dos modelos de produção. O capitalismo atual (financeiro), sob o viés neoliberal e globalizado, utiliza-se de avanços tecnológicos que acentuam a miséria e aumentam, sobremaneira, a concentração de renda entre as populações do planeta. 
A disseminação de conceitos neoliberais como a meritocracia e o empreendedorismo, busca justificar a exclusão de parte significativa da classe trabalhadora do mercado de trabalho. Nessa realidade, torna-se mais fácil a flexibilização das leis trabalhistas e a desregulamentação do mercado que culpabiliza aqueles que ficaram excluídos do sistema. Engendram-se, mais intensamente, a submissão aos ajustes fiscais e cortes de gastos sociais, para a manutenção dos ganhos de capital e a especulação voraz, além da financeirização da vida de forma generalizada (Mascarenhas, 2018).

Adicionadas, neste cenário, estão as constantes mudanças tecnológicas, que cobram do indivíduo a necessidade de dominar equipamentos e desenvolver modos de trabalho, que geram como efeito o medo do desemprego, o aumento da ansiedade em relação ao futuro e a aceitação de novas formações que atendam aos interesses do mercado. Estas transformações de comportamento em relação ao trabalho ou a prática de estar sempre "reciclando-se", contribuem para a redução da experiência.

Considerando as novas formas e relações de trabalho, Larrosa (2002) o difere da experiência, que por sua vez requer um gesto de interrupção quase impossível para os dias de hoje:

[...] parar para pensar, parar para olhar, parar para escutar, pensar mais devagar, olhar mais devagar, e escutar mais devagar; parar para sentir, sentir mais devagar, demorar-se nos detalhes, suspender a opinião, suspender o juízo, suspender a vontade, suspender o automatismo da ação, cultivar a atenção e a delicadeza, abrir os olhos e os ouvidos, falar sobre o que nos acontece, aprender a lentidão, escutar aos outros, cultivar a arte do encontro, calar muito, ter paciência e dar-se tempo e espaço (2002, p. 19).

A experiência se dá também nos espaços do silêncio, defendido por Deleuze (1992), requer um fazer-observar constante e um refazer-remodelar quando necessário, desconsiderando os apelos mercadológicos da agilidade, do cumprimento de metas, do funcionário padrão, etc. Para que o trabalhador se torne um funcionário padrão ou um empreendedor de sucesso, a vivência profissional requer os espaços temporais ocupados pelos fundamentos da economia de mercado, que giram em torno da otimização do tempo, assim é preciso fazer coisas que serão úteis no futuro e que melhorem sua posição social e seu currículo. Na lógica da otimização do tempo, até mesmo os momentos de lazer e de ócio precisam ser devidamente planejados, para poder extrair deles o máximo de produtividade, logo não há espaço para o saber da experiência, construído sobre a calmaria.

Por esta lógica, a vacância não planejada para ser funcional, passa a ser vista e sentida como desperdício e tédio, trazendo um sentimento de culpa ao indivíduo. Assim, a sociedade moderna requer uma quantidade maior de ações dentro de um determinado tempo. Associando essa lógica ao estudante, principalmente àquele oriundo das escolas periféricas, tantas vezes cobrado a estudar "para ser alguém na vida", seus dias estão milimetricamente planejados para as atividades divididas e compartimentalizadas no decorrer do ano letivo, como o cumprimento das componentes da grade curricular, as semanas de avaliações, a abertura e encerramento dos bimestres, os tempos de recuperação e as atividades dos projetos interdisciplinares. Compartimentando tempos e atividades, o estudante é adestrado ao modo de vida exigido pela sociedade da informação, que ele deverá compor enquanto futuro trabalhador.

\subsection{A educação financeira no contexto do biopoder}

O gerenciamento de recursos de forma racional sempre esteve presente ao longo do tempo, provisões para o futuro ou para momentos de crise sempre fizeram parte das mais diversas sociedades, um exemplo são as sociedades camponesas que apresentam práticas relacionadas ao anti-desperdício.

Contudo, somente a partir do século XIX, surgiram as primeiras campanhas com estímulo à prática da poupança por parte das classes mais populares, o que, no decorrer do tempo foi consolidando-se à racionalidade da ideologia neoliberal, gerando por sua vez, as iniciativas para a implantação da educação financeira. Neste contexto, a educação financeira faz parte 
do conjunto de estratégias das sociedades de controle que buscam minimizar a força política e maximizar a conformação dos sujeitos às condições sociais, sem apelar para os rígidos regulamentos disciplinares (Saraiva, 2017).

Para Foucault (2008b), a governamentalidade necessita das desigualdades, pois as estruturas do capitalismo asseguram esta produção como uma forma de estabelecer racionalidade política, que se atravessa em outros modos de vida.

Em entrevista à revista do Instituto Humanistas Unisinos, S. Lucarelli (2010), professor de Economia da Univertà Degli Studi di Bergamo (Itália), em 2010, expressa a mesma linha de pensamento de Foucault e considera a popularização da financeirização como uma estratégia do biopoder:

[...] financeirização (o que, em primeira instância, aparece como o deslocamento da poupança das economias domésticas para os títulos de ações), como a forma de controle social necessária para que a população contribua à reprodução das formas institucionais do novo capitalismo. O biopoder não é simplesmente uma forma de controle social, mas é um conjunto de técnicas de governo que representa um investimento na vida da parte das relações de poder (2010, s. p.)

A partir destas duas análises, infere-se que a educação financeira é um dos instrumentos utilizados para assegurar o aprofundamento de desigualdades, ao mesmo tempo em que é ferramenta de controle social, por ser também capaz de moldar condutas dentro dos grupos, estando assim à serviço do biopoder.

Os interesses do biopoder são instrumentalizar os trabalhadores com um letramento financeiro, levando-os a enfrentar, individualmente, os riscos e a prover suas necessidades. Desse modo, registra Saraiva (2017), a educação financeira é um complemento de austeridade às políticas neoliberais e uma ação de biopolítica, em que o Estado age como um conselheiro para substituir os mecanismos de proteção do trabalhador. As práticas de letramento financeiro, continua a autora, seriam um dos elementos que permite a reinterpretação da exploração da classe trabalhadora, neutralizando sua força política e minando sua capacidade de resistir e de formular alternativas ao projeto neoliberal.

Quando, a partir de sua leitura sobre a realidade do mundo atual, um dos principais documentos norteadores do sistema educacional brasileiro, a Base Nacional Comum Curricular - BNCC (2018), estabelece como desafio formar o novo perfil para o futuro trabalhador, ela se mostra organizada como uma efetiva ferramenta para a consolidação do biopoder.

[...] Observamos transformações nas formas de participação dos trabalhadores nos diversos setores da produção, a diversificação das relações de trabalho, a oscilação nas taxas de ocupação, emprego e desemprego, o uso do trabalho intermitente, a desconcentração dos locais de trabalho, e o aumento global da riqueza, suas diferentes formas de concentração e distribuição, e seus efeitos sobre as desigualdades sociais. Há hoje mais espaço para o empreendedorismo individual, em todas as classes sociais, e cresce a importância da educação financeira e da compreensão do sistema monetário contemporâneo nacional e mundial, imprescindíveis para uma inserção crítica no mundo atual (2018, p. 568) (grifo nosso).

As exigências para que a escola desenvolva ações curriculares que garantam as práticas do empreendedorismo individual, em conjunto com o letramento financeiro, lançam o estudante, futuro trabalhador, em um universo de incertezas. Ele deverá desenvolver habilidades que o tornem um empreendedor individual de sucesso, caso isto não ocorra, será o único culpado pelo seu suposto fracasso. Pois, não é possível que os milhões de jovens que precisam ingressar no mercado de trabalho anualmente, tornem-se empreendedores de sucesso.

Quando estabelece tais diretrizes, a macropolítica educacional reorganiza a forma de exploração da classe trabalhadora, neutralizando sua força política e minando sua capacidade de resistir e de formular alternativas ao projeto 
neoliberal (Saraiva, 2017), lança o jovem diretamente ao mercado estruturado pelo processo de "uberização do trabalho" ", quando ele deverá tornar-se um microempreendedor, até mesmo para oferecer serviços de entregas em domicílio. Nesse caso, a pejotização tornou-se um modelo comum trazendo consigo a corrosão dos direitos trabalhistas e o desemprego (Florêncio, et al, 2020).

Frente a este cenário, em que os interesses dos neoliberais cooptaram a escola e seus currículos, é difícil para um professor da componente curricular de Matemática abordar o tema da educação financeira de maneira descompromissada com o viés político que ela traz consigo. No entanto, uma maneira de romper com esse ciclo, é o professor desenvolver métodos alternativos e criativos, que fujam das cobranças que vêm sendo impostas pelo sistema de ensino brasileiro, como forma de atender aos interesses do ideário neoliberal (Gallo e Monteiro, 2020), uma destas possibilidades está na educação menor, "como ato de criação de possibilidades e de fuga do modelo instaurado" (Pacheco, 2020, p. 11), ela pode criar caminhos para subverter a ordem instituída sem, no entanto, modificar os propósitos do processo educacional.

\section{Considerações Finais}

O biopoder é uma forma de organização de estados, em sua maior parte neoliberais, para controlar politicamente suas populações e estabelecer sua governamentalidade. Esta última necessita das desigualdades, pois as estruturas do capitalismo asseguram sua produção como uma forma de estabelecer racionalidade política. A educação formal, representada pela escola é um dos campos relacionados à governamentalidade, assim, como Foucault discute nos tópicos acima, ela naturaliza os códigos de conduta, selecionando conhecimentos e impondo discursos de ordem judicial, linguística, religiosa, doméstica, etc, quando produz alguns modelos de pensamento e ignora outros, os quais considera inúteis, improdutivos, perigosos, anormais e inconformes.

Dentro deste contexto educacional, a educação financeira desenvolvida nos currículos escolares torna-se um dos instrumentos utilizados para assegurar o aprofundamento de desigualdades, ao mesmo tempo em que é ferramenta de controle social, por ser também capaz de moldar condutas dentro dos grupos, estando assim à serviço do biopoder.

Contudo, embora os modelos neoliberais que definem os posicionamentos da escola e transformam os educadores em meros administradores escolares ou reprodutores de conteúdos pré-determinados por um ementário a partir da construção de seus currículos, impondo dificuldades e até mesmo ameaçam as experiências progressistas na educação, existem tentativas de resistências que estão acontecendo nas escolas pelo país afora.

São resistências para enfrentar os processos de massificação instaurados pelo modo de produção vigente, entre as diversas possibilidades de resistência uma das é mesmo a educação menor, capaz de subverter a ordem, sem, contudo, negligenciar as atividades burocráticas relacionadas ao ofício de professor e ao processo educacional. Ela pode romper com as tarefas de reprodução de conteúdo e desenvolver, em conjunto com os alunos, o pensamento como criação.

Nestes espaços de resistências, a educação financeira pode construir saberes que potencializem a subjetividade dos alunos, pode produzir outras possibilidades, que vão além de simples modelos de comportamentos financeiros e que possibilite novas conexões e experimentações.

\footnotetext{
2 Termo relativamente novo de referência ao pioneirismo da empresa Uber em relação ao seu particular modelo de organização do trabalho, sem qualquer tipo de vínculos empregatícios entre o trabalhador e a empresa. Constitui-se por uma relação de prestação de serviços entre CNPJ x CNPJ, não mais entre CNPJ x CPF. Neste sistema há maior controle sobre o prestador de serviços ou o trabalhador autônomo que assumirá todos os riscos para a oferta dos serviços, assim como oferecendo a quase totalidade dos meios de produção necessários à execução da atividade e por eles, integralmente, se responsabilizando.
} 


\section{Referências}

Aguiar, K. F. \& Rocha, A, M. L. (2003). Pesquisa-Intervenção e a Produção de Novas Análises [versão eletrônica]. Psicologia Ciência e Profissão. 4(23), 6473. https://doi.org/10.1590/S1414-98932003000400010.

Deleuze, G. (1992). Conversações. Editora 34.

Deleuze, G. \& Guattari, F. (2010). O anti-Édipo: capitalismo e esquizofrenia. Ed. 34.

Efing, A. C. \& Resende, A. C. L. (2016). Educação para o consumo consciente: um dever do Estado [versão eletrônica], Revista Jurídico Brasileiro, 2(01), $713-746$.

Florêncio, A., Filho, Rosa, P. O. \& Marchiori, G. R. S. (2020). Do homo oeconomicus ao sujeito de desempenho: trajetória do sujeito no modelo neoliberal nos pensamentos de Foucault e Byung-Chul Han. Research, Society and Development, 9(4), 1-27. http://dx.doi.org/10.33448/rsd-v9i4.2964.

Foucault, M. (1988). História da Sexualidade I: a vontade de saber. Edições Graal.

Foucault, M. (1987). Vigiar e punir: nascimento da prisão. Vozes.

Foucault, M. (2008a). A Arqueologia do saber. Rio de Janeiro: Forense Universitária.

Foucault, M. (2008b). Nascimento da biopolítica. São Paulo: Martins Fontes.

Gallo, S. (2002). Em torno de uma educação menor [versão eletrônica]. Revista Educação e Realidade, 27(02), 169 - 178.

Gallo, S. (2013, setembro). Em torno de uma educação menor: variáveis e variações. Anais da 36 ${ }^{a}$ Reunião Nacional da ANPEd, Goiânia, GO, Brasil, 36.

Gallo, S. \& Monteiro, A. (2020). Educação menor como dispositivo potencializador de uma escola outra [versão eletrônica], REMATEC Revista de Matemática, Ensino e Cultura, 15(33), p.185- 200. 10.37084/REMATEC.1980-3141.2020.n33.p185-200.id228.

Grupo Transversal (2015). Educação Menor: conceitos e experimentações. Appris.

Larrosa, J. B. (2002). Notas sobre a Experiência e o Saber de Experiência [versão eletrônica], Revista Brasileira de Educação,(19), 20-28.

Lima, I. S., Neto \& Silva, F. V. (2021). O triângulo disciplina, biopolítica e governamentalidade na pandemia de Covid-19: um estudo de postagens de secretarias estaduais de educação no Instagram. Debates em Educação, 13(32), 348-373. https://doi.org/10.28998/2175-6600.2021v13n32p348-373.

Lucarelli, S. (2010). A financeirização como forma de biopoder [versão eletrônica]. Revista do Instituto Humanitas Unissinos, ed. 327(X), 5-10.

Mascarenhas, L. B. (2018). Biopolítica, Educação e Resistência na Contemporaneidade [versão eletrônica]. Educação \& Realidade, 43 (04), $1537-1554$. https://doi.org/10.1590/2175-623675587.

Ministério da Educação (1998). Parâmetros Curriculares Nacionais. Brasília: Secretaria de Educação Fundamental/MEC.

Ministério da Educação (2018). Base Nacional Comum Curricular: educação é a base. MEC.

Pacheco, D. C. Educação menor e desterritorialização do currículo. Dissertação de mestrado, Universidade Estadual Paulista, Presidente Prudente, SP, Brasil.

Prodanov, C. C. \& Freitas, E. C. (2013) Metodologia do trabalho científico: métodos e técnicas da pesquisa e do trabalho acadêmico. Feevale.

Santos, E. F. dos. (2005) O ensino superior no Brasil e os “Acordos MEC/USAID”: o intervencionismo norte-americano na educação brasileira. Dissertação de Mestrado, Universidade Estadual de Maringá, Maringá, PR, Brasil.

Saraiva, K. S. (2017). Os sujeitos endividados e a Educação Financeira. Educar em Revista, (66), 157-173. https://doi.org/10.1590/0104-4060.53867.

Savoia, J. R. F., Saito, A. T. \& Santana, F. A. (2007). Paradigmas da educação financeira no Brasil. Rev. Adm. Pública, 6(04), 1120-1141. https://doi.org/10.1590/S0034-76122007000600006. 